\title{
Decision making in a Fuzzy Environment with allowable shortages \& chance constraints for Multi - Items
}

\author{
Dr. Mrs.P. Parvathi, D. Chitra \\ Head \& Associate Professor, Department of Mathematics, Quaid-E -Millath Government College for Women \\ (Autonomous), Chennai-600002 \\ Assistant Professor, Department of Mathematics, Quaid- E-Millath Government College for Women \\ (Autonomous), Chennai-600002
}

\begin{abstract}
This paper explores a Mathematical model for obtaining the minimum total cost of Multi-items with Mult-objectives in a Fuzzy Environment. The paper incorporates four constraints such as warehouse space and the constraint, investment amount constraint, percentage of utilization of volume of the ware house space and the shortage level constraint by allowing shortages. The previous researchers had analyzed different models on this relevant topic without shortages. But this paper mainly focuses on model with shortages and above mentioned constraints.

Ware house maintenance is one of the essential parts of service operation. The ware house space in selling stores plays an important role in stocking the goods. In the proposed model, the ware house space is considered in volume. The demand is taken as function of unit cost price which is taken as triangular fuzzy number. This paper also includes a detailed numerical example to elucidate our proposed strategy.
\end{abstract}

Keywords: Inventory model, volume of the ware house, triangular fuzzy number, shortages, capital investment.

\section{Introduction}

Inventory means stock of goods for future use (production/sales). Inventory control is the major part of every enterprise in any sector of economy. In any industry, the inventories are essential, but they mean lockup of capital. The excess of demand would lead to a shortage which calls for controlling the inventories in the most profitable way by minimizing the relevant cost involved in this (Purchasing cost, holding cost, setup cost, shortage cost).

In any Inventory model space availability plays a vital role. Ware house space can be considered in terms of area / volume, but most of the researchers considered only area of the ware house space. Here, the ware house space in the selling store is considered in volume.

The classical inventory problem is designed by considering that the demand rate of an item is considered to be constant and independent in nature. In the competitive market the unit cost price and the demand of an item are interrelated. When the demand of an item is high, an item is produced in large numbers and fixed costs of production are spread over a large number of items. Hence the unit price of an item inversely relates to the demand of that item.

\section{Literature Survey}

Initially, the Fuzzy set theory is used in the decision making problem by Bellman and Zadeh [4]. The objectives are introduced as Fuzzy goals over the $\alpha$ - cut of a Fuzzy constraint set by Silver and Peterson [3]. Concept of solving a Multi-objectives problem is introduced in [4]. Multi-objective Fuzzy Inventory model is formulated with 3 constraints and solved by using geometric programming method by Zimmerman [5] Multiitem stochastic and Fuzzy stochastic inventory models are formulated in Debdulal Panda and Samarjit kar [6]. In all of the above articles, the ware house space available is taken in terms of area. If the warehouse space is taken in terms of volume, the less percentage of volume of the ware house space will be consumed.

Mr.G.M Arun prasath and Mr.C.V Seshaiah [7] have developed a Fuzzy Inventory model for multiitem multi-objectives with possible constraints. They did not allow shortages. In reality shortages occur in many inventory control problems. Hence this paper allows shortages (which are very natural in day to day life) which are completely backlogged. To optimize the proposed model, Lagrangean multiplier method is used in which unit cost price and lot sizes are taken as decision variables. Unit cost price is dealt in Fuzzy environment Defuzzification is done using signed distance method. Sensitivity analysis is carried out through numerical example to strengthen our paper. 


\section{Fuzzy Numbers}

\section{Methodology}

Any fuzzy subset of the real line $\mathrm{R}$, whose membership function $\mu_{\mathrm{A}}$ satisfied the following conditions, is a generalized fuzzy number $\tilde{A}$.

(i) $\mu_{\mathrm{A}}$ is a continuous mapping from $\mathrm{R}$ to the closed interval $[0,1]$,

(ii) $\mu_{\mathrm{A}}=0,-\infty<x \leq a_{1}$

(iii) $\mu_{\mathrm{A}}=\mathrm{L}(\mathrm{x})$ is strictly increasing on $\left[\mathrm{a}_{1}, \mathrm{a}_{2}\right]$

(iv) $\mu_{\mathrm{A}}=\mathrm{w}_{\mathrm{A}}, a_{2} \leq x \leq a_{3}$

(v) $\mu_{\mathrm{A}}=\mathrm{R}(\mathrm{x})$ is strictly decreasing on $\left[\mathrm{a}_{3}, \mathrm{a}_{4}\right]$

(vi) $\mu_{\mathrm{A}}=0, a_{4} \leq x \leq \infty$

where $0<\mathrm{w}_{\mathrm{A}} \leq 1$ and $\mathrm{a}_{1}, \mathrm{a}_{2}, \mathrm{a}_{3}$ and $\mathrm{a}_{4}$ are real numbers. Also this type of generalized fuzzy number be denoted as $\widetilde{A}=\left(a_{1}, a_{2}, a_{3}, a_{4} ; w_{A}\right)_{L R} ;$ when $\mathrm{w}_{\mathrm{A}}=1$,it can be simplified as $\widetilde{A}=\left(a_{1}, a_{2}, a_{3}, a_{4} ; w_{A}\right)_{L R}$.

\section{Triangular fuzzy number}

The fuzzy set $\widetilde{A}=\left(a_{1}, a_{2}, a_{3}\right)$ where $\mathrm{a}_{1}<\mathrm{a}_{2}<\mathrm{a}_{3}$ and defined on

$\mathrm{R}$, is called the triangular fuzzy number, if the membership function of $A$ is given by

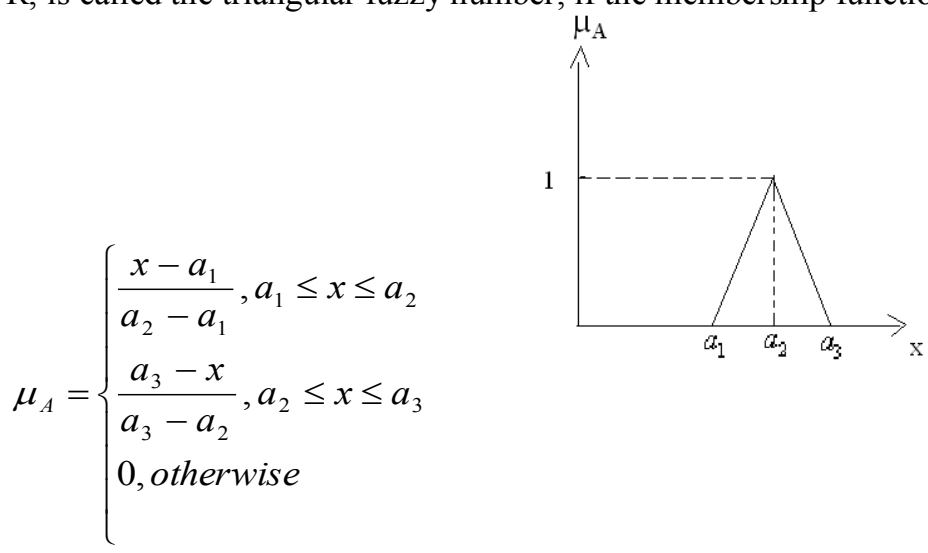

\section{The Function Principle}

The function principle was introduced by Chen [6] to treat fuzzy arithmetical operations. This principle is used for addition, subtraction, multiplication and division of fuzzy numbers.

Suppose $\widetilde{A}=\left(a_{1}, a_{2}, a_{3}\right)$ and $\widetilde{B}=\left(b_{1}, b_{2}, b_{3}\right)$ are two triangular fuzzy numbers. Then

(i) The addition of $\tilde{A}$ and $\widetilde{B}$ is

$$
\widetilde{A}+\widetilde{B}=\left(a_{1}+b_{1}, a_{2}+b_{2}, a_{3}+b_{3}\right) \text { where } \mathrm{a}_{1}, \mathrm{a}_{2}, \mathrm{a}_{3}, \mathrm{~b}_{1}, \mathrm{~b}_{2}, \mathrm{~b}_{3} \text { are any real numbers. }
$$

(ii) The multiplication of $\tilde{A}$ and $\widetilde{B}$ is $\widetilde{A} \times \widetilde{B}=\left(c_{1}, c_{2}, c_{3}\right)$

where $T=\left(a_{1} b_{1}, a_{1} b_{3}, a_{3} b_{1}, a_{3} b_{3}\right), c_{1}=\min T, c_{2}=a_{2} b_{2}, c_{3}=\max T$ if $\mathrm{a}_{1}, \mathrm{a}_{2}, \mathrm{a}_{3}, \mathrm{~b}_{1}, \mathrm{~b}_{2}, \mathrm{~b}_{3}$ are all non zero positive real numbers, then $\widetilde{A} \times \widetilde{B}=\left(a_{1} b_{1}, a_{2} b_{2}, a_{3} b_{3}\right)$.

(iii) $-\widetilde{B}=\left(-b_{3},-b_{2},-b_{1}\right)$ then the subtraction of $\widetilde{B}$ from $\widetilde{A}$ is $\widetilde{A}-\widetilde{B}=\left(a_{1}-b_{3}, a_{2}-b_{2}, a_{3}-b_{1}\right)$ where $a_{1}, a_{2}, a_{3}, b_{1}, b_{2}, b_{3}$ are any real numbers.

(iv) $\frac{1}{\widetilde{B}}=\widetilde{B}^{-1}=\left(\frac{1}{b_{3}}, \frac{1}{b_{2}}, \frac{1}{b_{1}}\right)$ Where $\mathrm{b}_{1}, \mathrm{~b}_{2}, \mathrm{~b}_{3}$ are all non zero positive real numbers, then the division of $\tilde{A}$ and $\widetilde{B}$ is $\frac{\widetilde{A}}{\widetilde{B}}=\left(\frac{a_{1}}{b_{3}}, \frac{a_{2}}{b_{2}}, \frac{a_{3}}{b_{1}}\right)$ 
(v) For any real number $\mathrm{K}$,

$$
\begin{aligned}
& \tilde{K A}=\left(K a_{1}, K a_{2}, K a_{3}\right) i f K>0 \\
& \tilde{K A}=\left(K a_{3}, K a_{2}, K a_{1}\right) i f K<0
\end{aligned}
$$

\section{Signed Distance Method}

Defuzzification of $\tilde{A}$ can be found by signed distance method. If $\tilde{A}$ is a triangular fuzzy number and is fully determined by $\left(\mathrm{a}_{1}, \mathrm{a}_{2}, \mathrm{a}_{3}\right)$, the signed distance from $\tilde{A}$ to 0 is defined as

$$
\begin{aligned}
d(\widetilde{A}, \widetilde{0}) & =\int_{0}^{1} d\left(\left[A_{L}(\alpha), A_{R}(\alpha)\right], \tilde{0}\right) d \alpha \\
& =\frac{\left(a_{1}+4 a_{2}+a_{3}\right)}{4}
\end{aligned}
$$

\section{Notations:}

$\mathrm{n}$ - number of items

I - total investment cost for replenishment

$\mathrm{L}$ - Inner length of the warehouse

B - Inner Breath of the ware house.

$\mathrm{M}$-Maximum height of the shelf

V- Volume of the ware house space for the items : $(\mathrm{i}=1,2, \ldots \mathrm{n})$

$D_{i}-D_{i}\left(p_{i}\right)$ demand rate (function of cost price) $(i=1,2, \ldots n)$

$\mathrm{y}_{\mathrm{i}}$ - lot size (a decision variable).

$\mathrm{K}_{\mathrm{i}}$ - Setup cost per cycle.

$\mathrm{p}_{\mathrm{i}}$ - price/unit item (a fuzzy decision variable)

$\widetilde{p}$ - fuzzy price /unit item

$1_{i}$ - length of the unit item $i$.

$b_{i}-$ breadth of the unit item $i$

$\mathrm{m}_{\mathrm{i}}-$ height of the unit item $\mathrm{i}$

$v_{i}-$ Volume of the unit item i

$\mathrm{Vw}$-percentage of utilization of volume of the ware house

$\mathrm{S}_{\mathrm{i}}$-shortage cost of the unit item i

$\mathrm{W}_{\mathrm{i}}$-shortage units till the next replenishment for ith item

$\mathrm{S}-$ Maximum shortage level for warehouse space.

\section{The Basic assumptions about the model are:}

1. Replenishment is instantaneous.

2. Shortages is allowed and completely backlogged

3. Lead time is zero.

4. Demand is related to the unit price as

$$
\mathrm{D}_{\mathrm{i}}=\frac{C_{i}}{p_{\underline{i}}^{e_{i}}}
$$

Where $C_{i}>0$ and $\mathrm{e}_{\mathrm{i}}\left(0<\mathrm{e}_{\mathrm{i}}<1\right)$ are constants and real numbers selected to provide the best fit of the estimated price function.

Volume of the unit item i defined by

$$
\mathrm{v}_{\mathrm{i}}=l_{i} \times b_{i} \times m_{i}
$$

Volume of the ware house space is defined by

$$
\mathrm{V}=L \times B \times M
$$

Fuzzy Inventory Model:

The total cost $=$ Purchasing cost + Set up cost + Holding cost + Shortage cost

From (1) 
$\operatorname{MinZ}=D_{i} \tilde{p}+\frac{D_{i} K_{i}}{y_{i}}+\frac{h_{i}\left(y_{i}-w_{i}\right)^{2}+S_{i} w_{i}^{2}}{2 y_{i}}$

For n- no. of items, our objective is to minimize the total cost

$\operatorname{MinZ}=\sum_{i=1}^{n}\left[D_{i} \tilde{p}+\frac{D_{i} K_{i}}{y_{i}}+\frac{h_{i}\left(y_{i}-w_{i}\right)^{2}+S_{i} w_{i}^{2}}{2 y_{i}}\right]$

Subject to some restrictions on available resources in Inventory problem that can not be ignored to derive the optimal total cost

First Constraint: The limitations on the available ware house space in the store,

$$
\sum_{i=1}^{n} v_{i} y_{i} \leq V
$$

Second Constraint: The upper limit of the total amount investment:

$$
\sum_{i=1}^{n} p_{i} y_{i} \leq I, \text { where } \mathrm{p}_{\mathrm{i},, \mathrm{y}_{\mathrm{i}}}>0
$$

Third Constraint: Percentage of utilization of volume of the ware house space.

$$
\begin{gathered}
\frac{V \times V_{w}}{\left(\sum_{i=1}^{n} v_{i} y_{i}\right) \times 100}=1 \\
0 \leq V_{w} \leq 100
\end{gathered}
$$

Fourth Constraint: Shortage level limitations

$$
\sum_{i=1}^{n} w_{i} \leq S
$$

Constructing Lagrangean function for ith item

$$
\begin{aligned}
& L\left(p_{i}, y_{i}, \lambda_{1}, \lambda_{2}, \lambda_{3}\right)=D_{i} \widetilde{p}_{i}+\frac{D_{i} K_{i}}{y_{i}} \\
& +\frac{h_{i}\left(y_{i}-w_{i}\right)^{2}+S_{i} w_{i}^{2}}{2 y_{i}} \\
& -\lambda_{1}\left(\sum_{i=1}^{n} v_{i} y_{i}-V\right)-\lambda_{2}\left(\sum_{i=1}^{n} p_{i} y_{i}-I\right)
\end{aligned}
$$

$$
-\lambda_{3}\left(\sum_{i=1}^{n} w_{i}-S\right)---(1)
$$

Where $\mathrm{D}_{\mathrm{i}}=\frac{C_{i}}{\widetilde{p}_{\underline{i}}^{e_{i}}}$

Subject to

$$
\frac{V \times V_{w}}{\left(\sum_{i=1}^{n} v_{i} y_{i}\right) \times 100}=1
$$


To minimize (1) with respect to $\mathrm{y}_{\mathrm{i}}$ and $\widetilde{p}_{i}$

$$
\begin{aligned}
\frac{\partial L}{\partial y_{i}}=- & \frac{C_{i} K_{i}}{\widetilde{p}_{i}^{e_{i}} y_{i}^{2}}+\frac{h_{i}\left(y_{i}^{2}-w_{i}^{2}\right)}{2 y_{i}^{2}} \\
& -\frac{S_{i} w_{i}^{2}}{2 y_{i}^{2}}-\lambda_{1} v_{i}-\lambda_{2} \widetilde{p}_{i} \\
\frac{\partial^{2} L}{\partial y_{i}^{2}}= & \frac{2 C_{i} K_{i}}{\widetilde{p}_{i}^{e_{i}} y_{i}^{3}}+\frac{h_{i} w_{i}^{2}}{y_{i}^{3}}+\frac{S_{i} w_{i}^{2}}{y_{i}^{3}}>0 \\
\frac{\partial L}{\partial \widetilde{p}_{i}}= & \left(1-e_{i}\right) C_{i} \widetilde{p}^{-e_{i}}-\frac{C_{i} K_{i}}{y_{i}} e_{i} \tilde{p}_{i}^{-e_{i}-1}-\lambda_{2} y_{i}
\end{aligned}
$$

$$
\begin{aligned}
\frac{\partial^{2} L}{\partial \widetilde{p}_{i}{ }^{2}}= & \left(e_{i}-1\right) e_{i} \tilde{p}^{-e_{i}-1} \\
& +e_{i}\left(1+e_{i}\right) \frac{C_{i} K_{i}}{y_{i}} \tilde{p}_{i}^{-e_{i}-2}>0
\end{aligned}
$$

The Lagrangean function satisfies the condition required for function to be minimum with respect to lot size $y_{\mathrm{i}}$ and unit cost price $\widetilde{p}_{i}$.

The minimum points are got by equating

$$
\frac{\partial L}{\partial y_{i}}=0 \text { and } \frac{\partial L}{\partial \tilde{p}_{i}}=0
$$

The expression for optimal lot size $y_{i}$ is

$$
y_{i}=\sqrt{\frac{\frac{2 C_{i} K_{i}}{\widetilde{p}_{i}{ }^{e_{i}}}+\frac{\left(h_{i}+S_{i}\right) w_{i}{ }^{2}}{2\left(\frac{h_{i}}{2}-\lambda_{1} v_{i}-\lambda_{2} \widetilde{p}_{i}\right)}}{2}}
$$

Optimal value of unit cost price $\widetilde{p}_{i}$ is got from (2) by using the value of $\mathrm{y}_{\mathrm{i}}$.

The model is illustrated for 1 item $(n=1)$

\section{Numerical Example:}

The values assumed for the given model are

$\mathrm{n}=1, \mathrm{C}_{1}=113, \mathrm{~K}_{1}=\$ 100 \mathrm{~h}_{1}=\$ 1, \widetilde{p}_{1}=\$(10,15,20) \& \mathrm{I}=\$ 1400$

$\mathrm{l}_{1}=2 \mathrm{~m}, \mathrm{~b}_{1}=3 \mathrm{~m}, \mathrm{~m}_{1}=4 \mathrm{~m}, \mathrm{~L}=10 \mathrm{~m}$,

$\mathrm{B}=12 \mathrm{~m}, \mathrm{M}=30 \mathrm{~m}, \mathrm{w}_{1}=16$ units,

$\mathrm{S}_{1}=\$ 300$

Now from the given values

$\mathrm{v}_{1}=24 \mathrm{~m}^{3}$ and $\mathrm{V}=3600 \mathrm{~m}^{3}$

Optimal solution of proposed model for different values of $\mathrm{e}_{1}$ (defuzzified values) 
Decision making in a Fuzzy Environment with allowable shortages \& chance constraints For Multi -

\begin{tabular}{|l|l|l|l|l|l|l|}
\hline $\mathrm{e}_{1}$ & $\mathrm{p}_{1}$ & $\mathrm{y}_{1}$ & $\mathrm{~V}_{\mathrm{w}}$ & $\mathrm{z}$ & $\begin{array}{l}\text { Cost/Item } \\
\text { present paper }\end{array}$ \\
\hline 0.850 & 1.64 & 143.240 & 95.09 & 498.10 & 3.48 & \\
\hline 0.860 & 1.685 & 142.730 & 95.15 & 497.33 & 3.83 \\
\hline 0.865 & 1.71 & 142.49 & 94.90 & 496.98 & 3.48 & \\
\hline 0.870 & 1.73 & 142.26 & 94.84 & 496.61 & 4.07 & 3.50 \\
\hline 0.885 & 1.80 & 141.53 & 94.35 & 495.35 & 3.20 & 6.52 \\
\hline
\end{tabular}

\section{Conclusion:}

In this paper mathematical model for multi - items with chance constraints in fuzzy environment is developed to obtain minimum total cost of the system with allowable shortages.

Focused on allowing shortages for each item, this model could be able to obtain less production cost due to increased demand thereby increasing order quantity. This result also reveals optimal percentage of utilization of the volume of the warehouse space.

This paper reveals that system saving percentage increases when the demand increases thereby decreasing production unit cost along with shortages. A signed distance method has been applied to get the defuzzified values of unit production cost and is tabulated for different values of $\mathrm{e}_{1}$.

This paper can be extended for model with all parameters in a fuzzy environment.

[1]. Inventory systems by Eliezer Naddor

\section{References}

[2]. Fuzzy sets and logics by Zadeh

[3]. E.A Silver, R. Peterson, Decision systems for Inventory Management and production planning, New York: John Wiley, 1985

[4]. R.E. Bellman, L.A Zadeh, "Decision- making in a fuzzy environment", Management science, 17(4), B141-B164, 1970.

[5]. H.J. Zimmermann, "Description and optimization of fuzzy systems", Internet. J. General systems 2(4), 209-215,1976

[6]. Debdul Panda, Samarjit Kar, "Multi - item stochastic and fuzzy - stochastic inventory models under imprecise goal and cjhance constraints" Advanced modeling in optimization, (7), 155-167, 2005.

[7]. G.M Arun Prasath, C.V Seshaiah, "Multi-item multi objective fuzzy inventory model with possible constraints"ARPN Journal of Science and Technology VOL 2 NO 7 ,August 2012.

[8]. K.S Park, "Fuzzy set theoretic interpretation of economic order quantity", IEEEE Trans. Systems Man cybernet, 17(6), 1082-1084 ,1987.

[9]. Nirmal Kumar Mandal, ET. Al., "Multi-objective fuzzy inventory model with three constraints: a geometric programming approach". Fuzzy sets and Systems, (150), 87-106,2005

[10]. H. Tanaka, et al., "On fuzzy mathematical programming", J. Cybernet,3(4), 37-46,1974

[11]. G.M Arun Prasath, C.V Seshaiah, " Optimization of total expenditure by using multi-objective fuzzy inventory model and warehouse location problem", European Journal of Scientific Research, 58(1),38-43,2011 